\title{
ANALISIS EKONOMI BAGAN PERAHU DI KECAMATAN PONELO KEPULAUAN
}

\author{
Economic Analysis of Boat Chart in Ponelo Island Sub-District
}

\author{
Oleh: \\ Muh. Yasin Umsini Putra Oliii ${ }^{1 *}$, Sintia Buheli ${ }^{1}$, Sri Yuningsih Noor ${ }^{1}$ \\ ${ }^{1}$ Program Studi Perikanan, Universitas Gorontalo, Indonesia \\ *Korespondensi penulis: muhammadyasinumsiniputraolii@gmail.com
}

\begin{abstract}
ABSTRAK
Sumberdaya perikanan di Kabupaten Gorontalo Utara adalah salah satu potensi yang dapat dijadikan sebagai penopang perekonomian masyarakat khususnya bagi masyarakat yang memiliki profesi sebagai nelayan. Kabupaten Gorontalo Utara memiliki sektor perikanan yang didominasi oleh perikanan skala kecil, hat tersebut ditandai dengan banyaknya penggunaan alat tangkap sederhana yang digunakan oleh nelayan. Bagan perahu merupakan satu dari banyaknya alat tangkap yang banyak dioperasikan oleh nelayan tradisional di Kecamatan Ponelo Kepulauan. Riset ini dilakukan untuk menganalisis keuntungan yang diperoleh dari pengoperasian alat tangkap bagan perahu di Kecamatan Ponelo Kepulauan, Kabupaten Gorontalo Utara. Metode yang digunakan dalam penelitian ini adalah metode survei dengan studi kasus dan dianalisis secara deskriptif. Analisis ekonomi yang digunakan untuk menghitung pendapatan usaha perikanan tangkap pada bagan perahu yaitu analisis total biaya, analisis pemasukan dan analisis keuntungan. Hasil riset menunjukkan total biaya yang dibutuhkan bagan perahu lampu putih dan lampu biru sebesar Rp3.142.000 yang didapat dari biaya tetap yang ditambahkan dengan biaya variabel. Jumlah pendapatan yang didapatkan oleh nelayan bagan perahu lampu biru lebih yaitu sebesar Rp34.005.000 sedangkan pendapatan bagan perahu lampu biru sebesar Rp31.870.000. Pendapatan atau keuntungan akhir yang didapat oleh nelayan bagan perahu selama melakukan 8 kali trip yaitu bagan perahu lampu putih sebesar Rp14.284.000 dan bagan perahu lampu biru sebesar Rp15.351.500.
\end{abstract}

Kata kunci: alat tangkap, bagan, nelayan, keuntungan

\begin{abstract}
Fisheries resources in Gorontalo Utara Regency are one of the potentials that can be used as a support for the community's economy, especially for people who have a profession as fishermen. Gorontalo Utara Regency has a fisheries sector that is dominated by small-scale fisheries, this hat is indicated by the large number of simple fishing gear used by fishermen. The boat chart is one of the many fishing gears operated by traditional fishermen in Ponelo Kepulauan Sub-district. This research was conducted to analyze the benefits obtained from the operation of boat chart fishing gear in Ponelo Kepulauan Sub-district, Gorontalo Utara Regency. Case studies survey method used in this research and descriptive data analysis. The economic analysis used to calculate the capture fisheries business income on the boat chart is a total cost analysis, an income analysis, and a profit analysis. Research results show that the total cost required for white light and blue light boat chart is Rp3,142,000 obtained from fixed costs and variable costs. The amount of income obtained by the blue light boat chart fisherman is more than Rp34.005.000 while the blue light boat chart income is Rp31.870.000. The final income or profit earned by the boat chart fisherman during 8 trips, namely the white light boat chart of Rp14,284,000 and the blue light boat chart of Rp15,351,500.
\end{abstract}

Key words: boat chart, fisherman, fishing gear, profit

\section{PENDAHULUAN}


Kabupaten Gorontalo Utara memiliki sumberdaya perikanan yang berasal kegiatan perikanan budidaya dan perikanan tangkap. Berdasarkan pengelompokkan wilayah pengelolaan perikanan (WPP), Kabupaten Gorontalo Utara berada pada WPP 716 yang meliputi Laut Sulawesi sampai Samudera Pasifik bagian utara pulau Halmahera dan Papua. Wilayah tersebut berpotensi memiliki sumberdaya perikanan tangkap yang cukup besar. Hal tersebut didukung dengan adanya data hasil produksi perikanan tangkap di Kabupaten Gorontalo Utara tahun 2015 mencapai 23.563,60 ton (BPS Gorontalo 2015). Kegiatan perikanan tangkap yang ada di Kabupaten Gorontalo Utara didominasi oleh perikanan skala kecil. Hal tersebut ditandai dengan masih banyaknya alat tangkap yang bersifat sederhana yang digunakan oleh nelayan, khususnya nelayan di Kecamatan Ponelo Kepulauan. Bagan perahu merupakan satu dari sekian banyak alat yang banyak digunakan oleh nelayan di Kecamatan Ponelo Kepulauan.

Bagan perahu adalah salah satu contoh alat tangkap jenis jaring angkat (lift net) yang membutuhkan alat bantu penangkapan berupa cahaya atau lampu dalam melakukan operasi penangkapan (Nelwan et al. 2015). Bagan perahu membutuhkan alat bantu penangkapan berupa cahaya atau lampu untuk menarik perhatian ikan agar berkumpul di sekitar alat tangkap. Pengoperasian alat tangkap ini dilakukan pada malam hari dan tidak dimungkinkan untuk dioperasikan pada siang hari atau pada saat bulan bersinar karena akan mempengaruhi jumlah hasil tangkapan. Waktu yang efektif untuk digunakan dalam operasi penangkapan menggunakan bagan perahu yaitu pada saat hari sudah mulai gelap atau pada saat terbenamnya matahari sampai menjelang fajar.

Masyarakat di Kecamatan Ponelo Kepulauan yang memiliki profesi atau mata pencaharian sebagai nelayan sangat bergantung pada potensi perikanan tangkap, di mana sektor tersebut diharapkan dapat menjadi penopang perekonomian bagi nelayan. Hal tersebut dapat terwujud dengan adanya kebijakan yang dibuat oleh pemerintah untuk mengembangkan bidang perikanan tangkap. Menurut Baruadi et al. (2012) pemerintah Kabupaten Gorontalo Utara pada tahun 2010 membuat kebijakan minapolitan, kebijakan tersebut merupakan bagian dari pilot project program yang ada di Indonesia. Kebijakan minapolitan dibentuk dengan harapan dapat mengoptimalkan pengelolaan sumberdaya ikan untuk meningkat pendapatan masyarakat yang berprofesi sebagai nelayan.

Kegiatan perikanan tangkap menggunakan bagan perahu telah banyak dilakukan oleh pelaku usaha perikanan di Kabupaten Gorontalo Utara khususnya nelayan di Pulau Ponelo. Banyak nelayan yang menggunakan alat tangkap bagan perahu dan mendaratkan hasil tangkapannya di Pelabuhan Perikanan Nusantara (PPN) Kwandang Gorontalo Utara (Amrain et al. 2015). Banyaknya usaha penangkapan yang dilakukan dengan menggunakan bagan perahu tidak diiringi dengan informasi pendapatan yang diperoleh nelayan perahu, sehingga perlu dilakukan analisis ekonomi untuk mengetahui seberapa besar nelayan bagan perahu di Kecamatan Ponelo Kepulauan dalam memperoleh keuntungan.

\section{METODE PENELITIAN}

Riset ini dilaksanakan di perairan Kecamatan Panelo Kepulauan, Kabupaten Gorontalo Utara pada bulan Maret-April tahun 2019. Metode yang digunakan dalam riset ini adalah metode survei dengan studi kasus. Pengambilan data dilakukan dengan 8 kali trip sesuai dengan waktu operasi nelayan dengan 2 minggu sekali selama 2 bulan. Data yang didapat selanjutnya dianalisis secara deskriptif. Analisis ekonomi yang digunakan untuk menghitung pendapatan usaha tangkap bagan perahu yaitu:

\section{Analisis Total Biaya}

Total biaya ( Total Cost) merupakan hasil penjumlahan dari total jumlah biaya tetap dan biaya variabel dalam kegiatan usaha perikanan tangkap (Ashari 2011 dalam Ikram 2016). Rumus yang digunakan untuk menghitung total biaya yaitu:

$$
\mathrm{TC}=\mathrm{FC}+\mathrm{VC}
$$


Keterangan:

$\begin{array}{ll}\mathrm{TC}(\text { Total Cost }) & =\text { Total biaya/pengeluaran }(\mathrm{Rp}) \\ \mathrm{FC}(\text { Fixed Cost }) & =\text { Biaya tetap }(\mathrm{Rp}) \\ \text { VC }(\text { Variable Cost }) & =\text { Biaya varibel }(\mathrm{Rp})\end{array}$

\section{Analisis Total Penerimaan}

Total penerimaan (Total Revenue) merupakan total dari hasil yang diterima dalam kegiatan usaha tangkap (Ashari 2011 dalam Ikram 2016). Rumus yang digunakan untuk menghitung total penerimaan yaitu:

$$
\mathrm{TR}=\mathrm{P} \times \mathrm{R}
$$

Keterangan:

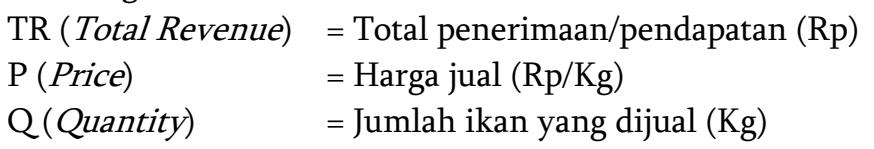

\section{Analisis Keuntungan}

Keuntungan adalah hasil akhir yang didapatkan nelayan setelah dikurangi oleh total biaya dalam usaha tangkap selama satu kali proses produksi (Ashari 2011 dalam Ikram 2016). Rumus yang digunakan untuk menghitung keuntungan yaitu:

$$
\pi=\mathrm{TR}-\mathrm{TC}
$$

Keterangan:

$$
\begin{array}{ll}
\pi & =\text { Keuntungan }(\mathrm{Rp}) \\
\mathrm{TR}(\text { Total Revenue) } & =\text { Total penerimaan/ pendapatan }(\mathrm{Rp}) \\
\mathrm{TC}(\text { Total Cost }) & =\text { Total biaya/pengeluaran }(\mathrm{Rp})
\end{array}
$$

\section{HASIL DAN PEMBAHASAN}

\section{Analisis Total Biaya}

Analisis total biaya didapat dengan cara mengetahui jumlah biaya tetap dan jumlah biaya variabel. Biaya tetap (fixed cost) adalah biaya yang tidak mengalami perubahan secara total meskipun terjadi peningkatan maupun penurunan dalam aktivitas bisnis tersebut (Winarko dan Astuti 2018). Biaya tetap pada unit penangkapan bagan perahu yang dikeluarkan selama 8 kali trip disajikan pada Tabel 1.

Tabel 1. Total Biaya Tetap Bagan Perahu 8 kali trip

\begin{tabular}{ccc}
\hline Modal Kerja & Jumlah & Biaya (Rp) \\
\hline Solar & 60 liter & 600.000 \\
Bensin & 80 liter & 840.000 \\
Beras & 40 liter & 400.000 \\
Rokok & 16 bungkus & 80.000 \\
Bawang, Rica, Tomat & - & 400.000 \\
Es batu & 400 biji & 800.000 \\
Gas elpiji & 1 tabung & 22.000 \\
\hline & & \\
\hline
\end{tabular}

Berdasarkan Tabel 1 diketahui total biaya tetap bagan perahu selama 8 kali trip di Kecamatan Ponelo Kepulauan yaitu sebanyak Rp3.142.000. Biaya tetap bagan perahu yang menggunakan lampu warna putih dan lampu warna biru terdiri dari bahan bakar solar dan bensin, beras, rokok, bawang, rica, tomat, gas elpiji dan es batu. Untuk mendapatkan nilai total biaya maka perlu diketahui jumlah biaya variabel yang dikeluarkan. Menurut Mulyadi (2009), biaya variabel akan berubah jumlahnya sebanding dengan terjadinya perubahan 
volume kegiatan. Biaya variabel bagan perahu selama 8 kali trip yaitu biaya pembelian lampu bagan warna putih dan lampu warna biru. Biaya variabel disajikan pada Tabel 2.

Tabel 2. Total Biaya Variabel Bagan Perahu Selama 8 Kali Trip

\begin{tabular}{|c|c|c|}
\hline Jenis Variabel & Jumlah & Biaya (Rp) \\
\hline Lampu Putih & 4 & 160.000 \\
\hline Lampu Biru & 4 & 160.000 \\
\hline \multicolumn{2}{|c|}{ Total } & 320.000 \\
\hline
\end{tabular}

Tabel 2 menunjukkan total biaya variabel bagan perahu selama 8 kali trip yaitu sebesar Rp320.000 dengan biaya lampu warna putih yaitu sebesar Rp160.000 dan biaya pembelian lampu warna biru sebesar Rp160.000. Nilai tersebut dapat digunakan untuk menentukan total biaya pengeluaran bagan perahu. Analisis total biaya pengeluaran bagan perahu yang dikeluarkan selama 8 kali trip disajikan pada Tabel 3.

Tabel 3. Analisis Biaya Pengeluaran Bagan Perahu Selama 8 Kali Trip

\begin{tabular}{cc}
\hline Jenis Biaya & Biaya (Rp) \\
\hline Biaya Tetap & 3.142 .000 \\
Biaya Variabel & 320.000 \\
\hline Total & 3.462 .000 \\
\hline
\end{tabular}

Tabel 3 menunjukkan total biaya pengeluaran bagan perahu selama 8 kali trip yaitu sebesar Rp3.462.000 dari hasil penjumlahan dari biaya tetap sebanyak Rp3.142.000 dan rata-rata biaya variabel sebanyak Rp320.000. Total biaya pengeluaran bagan perahu yang menggunakan lampu warna putih dan lampu warna biru selama 8 kali trip memiliki jumlah biaya pengeluaran yang sama. Menurut Silallahi et al. (2014) salah satu faktor yang mempengaruhi pendapatan nelayan adalah modal, pendapatan akan meningkat jika modal yang dikeluarkan besar. Sebagai contoh, jika nelayan membeli alat tangkap yang baik dengan modal yang cukup besar maka akan menghasilkan hasil tangkapan yang besar sehingga berpengaruh terhadap pendapatan nelayan yang ikut meningkat.

\section{Analisis Total Penerimaan}

Total penerimaan bagan perahu yang menggunakan lampu warna putih yaitu hasil penjualan ikan 8 jenis ikan. Total penerimaan bagan perahu menggunakan lampu warna putih selama 8 kali trip disajikan pada Tabel 4.

Tabel 4. Total Penerimaan Bagan Perahu Lampu Warna Putih selama 8 kali trip

\begin{tabular}{cccc}
\hline Jenis ikan & Hasil Tangkapan $(\mathrm{Kg})$ & Harga/satuan $(\mathrm{Rp})$ & Jumlah $(\mathrm{Rp})$ \\
\hline Teri Gelagar & 700 & 25.000 & 17.500 .000 \\
Kembung & 21 & 10.000 & 210.000 \\
Cumi-Cumi & 10 & 25.000 & 250.000 \\
Petek & 63 & 15.000 & 945.000 \\
Kuwe & 11 & 50.000 & 550.000 \\
Tembang & 113 & 5.000 & 565.000 \\
Tongkol & 24 & 25.000 & 600.000 \\
Teri Galer & 450 & 25.000 & 11.250 .000 \\
\hline & Total & & 31.870 .000 \\
\hline
\end{tabular}

Total penerimaan bagan perahu menggunakan lampu warna putih yaitu sebesar Rp31.870.000. Nilai tersebut didapat dari penjualan ikan hasil tangkapan bagan perahu yang terdiri dari ikan teri gelagar, ikan kembung, cumi-cumi, ikan petek, ikan kuwe, ikan tembang, ikan tongkol dan teri galer. Total penerimaan bagan perahu menggunakan lampu warna biru yaitu dari hasil penjualan 9 jenis ikan tangkapan. Menurut Dahen (2016) pendapatan akan meningkat jika kemampuan faktor produksi menghasilkan output meningkat. 
Tingkat konsumsi ikan laut di Kabupaten Gorontalo utara lebih tinggi baik dalam bentuk ikan segar maupun hasil olahan dibandingkan dengan tingkat konsumsi ikan laut di daerah lain yang ada di Provinsi Gorontalo (Astuti dan Tebai 2018). Hal tersebut yang menyebabkan hasil tangkapan mudah dipasarkan oleh nelayan. Total penerimaan bagan perahu menggunakan lampu warna biru selama 8 kali trip disajikan pada Tabel 5.

Tabel 5. Penerimaan Bagan Perahu Lampu Warna Biru selama 8 kali Trip

\begin{tabular}{cccc}
\hline Jenis ikan & Hasil Tangkapan $(\mathrm{Kg})$ & Harga/satuan $(\mathrm{Rp})$ & Jumlah \\
\hline Teri Gelagar & 750 & 25.000 & 18.750 .000 \\
Kembung & 23 & 10.000 & 230.000 \\
Tongkol & 5 & 25.000 & 125.000 \\
Tembang & 57 & 5.000 & 285.000 \\
Pari Macan & 8 & 100.000 & 800.000 \\
Petek & 56 & 15.000 & 840.000 \\
Teri Galer & 500 & 25.000 & 12.500 .000 \\
Kuwe & 3 & 50.000 & 150.000 \\
Cumi-Cumi & 13 & Rp25.000 & 325.000 \\
\hline & Total & & 34.005 .000 \\
\hline
\end{tabular}

Total penerimaan bagan perahu menggunakan lampu warna putih yaitu sebesar Rp34.005.000. Nilai tersebut didapat dari hasil penjualan ikan hasil tangkapan bagan perahu lampu biru yang terdiri 9 ikan. berdasarkan Tabel 4 dan 5, ikan teri memiliki nilai produksi paling besar di antara ikan yang lainnya. Menurut Astuti dan Tebai (2018), ikan teri dimanfaatkan oleh sebagian besar nelayan tradisional di Kabupaten Gorontalo Utara sebagai bahan makanan untuk dikonsumsi baik dalam bentuk ikan segar maupun ikan kering.

\section{Analisis Keuntungan}

Menurut Effendi dan Oktariza (2006), keuntungan merupakan hal yang harus dihasilkan oleh pelaku usaha perikanan agar usaha perikanan tetap dapat berkelanjutan. Keuntungan bagan perahu menggunakan lampu warna putih dan bagan perahu yang menggunakan lampu warna biru disajikan pada Tabel 6 .

Tabel 6. Keuntungan Bagan Perahu selama 8 kali trip

\begin{tabular}{ccc}
\hline Uraian & \multicolumn{2}{c}{ Bagan Perahu } \\
\cline { 2 - 3 } & Warna Putih & Warna Biru \\
\hline Total Pemasukan & 31.870 .000 & 34.005 .000 \\
Total Biaya Pengeluaran & 3.302 .000 & 3.302 .000 \\
Pendapatan & 28.568 .000 & 30.703 .000 \\
Ongkos ABK & 14.284 .000 & 15.351 .500 \\
\hline Keuntungan & 14.284 .000 & 15.351 .500 \\
\hline
\end{tabular}

Berdasarkan data yang tertera pada Tabel 6 menunjukkan total pendapatan yang diperoleh pada operasi penangkapan bagan perahu selama 8 kali trip yang menggunakan lampu warna putih sebesar Rp28.568.000 dan bagan perahu menggunakan lampu warna biru sebesar Rp30.703.000. Jumlah keuntungan akhir didapatkan dari pengurangan ongkos ABK yaitu sebesar 50\% dari hasil pendapatan. Sehingga keuangan bagan perahu menggunakan lampu warna putih selama 8 kali trip yaitu sebesar Rp14.284.000 dan bagan perahu menggunakan lampu warna biru sebesar Rp15.351.500.

\section{KESIMPULAN DAN SARAN}

Keuntungan bagan perahu di Kecamatan Ponelo Kabupaten Gorontalo Utara selama 8 kali trip yang menggunakan lampu warna putih sebesar Rp14.284.000 dan bagan perahu menggunakan lampu warna biru 
sebesar Rp15.351.500 hasil tersebut didapatkan dari total pemasukan dan pengeluaran yang diperoleh oleh nelayan bagan perahu.

\section{DAFTAR PUSTAKA}

Amrain F, Oliii AH, Baruwadi ASR. 2015. Produktifitas dan Kelayakan Usaha Bagan Perahu di Pelabuhhan Perikanan Nusantara Kwandang Kabupaten Gorontalo Utara. Jurnal Ilmiah Perikanan dan Kelautan. 3(4): 147-151.

Astuti I, Tebai, P. 2018. Analisis Formalin Ikan Teri (Stolephoris sp) Asin di Pasar Tradisional Kabupaten Gorontalo. Fisheries Journal. 1(1): 43-59.

[BPS] Badan Pusat Statistika Kabupaten Gorontalo. 2015. Jumlah Produksi Perikanan Tangkap Menurut Jenis Ikan di Kabupaten Gorontalo Utara. Gorontalo Utara [ID]: BPS.

Baruadi ASR, Simbolon D, Purbayanto A, Yusfiandayani R. 2012. Model Pengembangan Perikanan Tangkap Berbasis MInapolitan di Kabupaten Gorontalo Utara. Jurnal Teknologi Perikanan dan Kelautan. 3(1): $1-9$.

Dahen LD. 2016. Analisis Pendapatan Nelayan Pemilik Payang di Kecamatan Koto Tangah Kota Padang. Journal of Economic and Economic Education. 5(1): 47-57.

Effendi I, Oktariza W. 2006. Manajemen Agribisnis Perikanan. Jakarta [ID]: Penebar Swadaya.

Mulyadi, 2009. Akuntansi Biaya. Yogyakarta [ID]: STIE YPKPN.

Ningsih RS, Mudzakir AK, Rosyid A. 2013. Analisis Kelayakan Finansial Usaha Perikanan Payang Jabur (Boat Seine) di Pelabuhan Perikanan Pantai Asemdoyong Kabupaten Pemalang. Journal of Fisheries Resources Utilization Management and Technology. 2(3): 223-232.

Nelwan AFP, Sudirman, Nursam M, Yunus MA. 2015. Produktivitas Penangkapan Ikan Pelagis di Perairan Kabupaten Sinjai pada Musim Peralihan Barat-Timur. Jurnal Perikanan. 17(1): 18-26.

Winarko SP, Astuti P. 2018. Analisis Cost-Volume-Profit Sebagai Alat Bantu Perencanaan Laba (Multi Produk) pada Perusahaan Pia Latief Kediri. Jurnal Nusantara Aplikasi Manajemen Bisnis. 3(2): 9-21.

Silallahi AD, Diansyah, SWM. 2014. Analisis Faktor-Faktor Yang Mempengaruhi Pendapatan Nelayan. Jurnal Kultura. 15(1): 4414-4421. 